\title{
Subsidence, tremors and society
}

\author{
H.J. Gussinklo1, 2, H.W. Haak ${ }^{3}$, R.C.H. Quadvlieg ${ }^{2}$, P.M.F.M. Schutjens ${ }^{4}$ \\ \& L. Vogelaar ${ }^{5}$ \\ 1 Corresponding author; mail: NAM, P.O. box 28000, 9400 HH Assen \\ ${ }^{2}$ NAM \\ ${ }^{3}$ KNMI \\ 4 SIEP-RTS \\ 5 Commissie Bodemdaling Groningen
}

Manuscript received 29 May 1999; accepted in revised form 18 May 2000

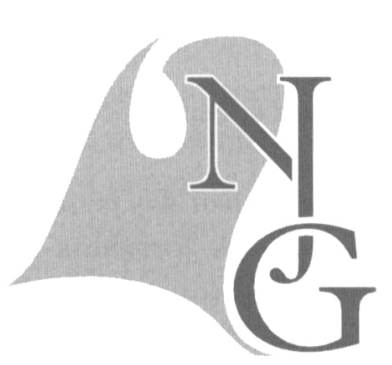

\begin{abstract}
The province of Groningen is flat and level, lying at an elevation close to sea level. The area is intensely cultivated and water table levels are a matter of concern. When the size of the Groningen gasfield was recognized in the sixties, it was realized, that substantial subsidence might occur at the surface affecting a large area.

Intensive studies were performed over time to predict future subsidence. These studies are supported by theoretical and experimental research in Shell since the 1950's concerning reservoir compaction and related surface subsidence. To monitor reservoir compaction and surface subsidence on a regular basis, an extensive monitoring program was set up by NAM. The program comprises leveling surveys, GPS measurements, measurements of shallow formation compaction and in-situ reservoir compaction.

In Groningen weak earthquakes have occurred since 1991 at irregular intervals. A multidisciplinary study from 1991-1993 on the relationship between gas production and earthquakes in the northern part of the Netherlands, combined with further studies concluded, that under certain circumstances these earthquakes may result from gas production. Monitoring is carried out through a seismic observation network with borehole sensors and locally installed accelerometers.

Because of the expected impact of subsidence induced by gas production on surface water management, an Agreement was concluded between the Province of Groningen and NAM.

In line with the 1983 Agreement the 'Commissie Bodemdaling' was founded, in which both NAM and the Province of Groningen are represented. On the basis of NAM predictions and actual measurements this Committee determines, what measures are to be taken to prevent, minimize or to correct for effects of gas production induced surface subsidence.
\end{abstract}

Keywords: North Netherlands, Groningen, Drente, gas production, compaction, subsidence studies, tremors, society, remedial projects

\section{Introduction}

During the last 4 decades subsidence of the land surface has received increasing attention in the Netherlands. The observed subsidence of the area overlying the gasfields in the northeastern provinces was one of the contributing factors. Moreover, the fact, that climatic change might cause major sea level rise has directed the attention to the amount and rate of subsidence in view of future water management measures. Since subsidence can have a substantial impact on water management, an accurate prediction of the ultimate amount of surface subsidence is required. It is important to discriminate between subsidence caused by compaction of deep formations due to gas production and subsidence caused by the consolidation of the shallow (Holocene) sediments.

To monitor reservoir compaction and surface subsidence in Groningen on a regular basis, an extensive monitoring program was set up by Nederlandse Aardolie Maatschappij B.V. (NAM). This program in- 
cludes yearly leveling surveys, Global Positioning Surveys, measurements of shallow formation compaction ( $0-400 \mathrm{~m}$ below surface) and in-situ reservoir compaction measurements in deep observation wells, drilled specifically for this purpose.

Prognoses of gas production induced surface subsidence are made, in line with the 1983 Subsidence Agreement between the Province of Groningen and NAM, as required by the State Supervision of Mines. In the year 2050, when it is planned to abandon the gasfield, the maximum subsidence over the center of the field is expected to be between 40 and $45 \mathrm{~cm}$.

Since 1986 earth tremors do occur in the northern part of the Netherlands. This area is considered aseismic, no earthquakes of any significance have been reported before. This situation is different from the Brabant and Limburg areas. (ref. the 1932 Uden earthquake and the 1992 Roermond earthquake). Therefore, the earth tremors in the northern Netherlands are a new phenomenon, the aerial distribution of which seems to coincide with the areas of gas production.

From 1991 - 1993 a multidisciplinary research project was conducted to investigate the relationship between gas production and earthquakes. The study concluded, that under certain circumstances earthquakes do result from gas production. It was recommended to establish an optimal seismic observation network for the northern part of the Netherlands. Eight (borehole) seismometer stations were installed in the provinces Drente and Groningen.

\section{Subsidence forecasts}

The large size of the Groningen gasfield, discovered in 1959, was not recognized until the mid sixties. The field is now known to extend over an area of approximately $900 \mathrm{~km}^{2}$. The Rotliegend (Permian) sandstone reservoir at a depth of approximately $2900 \mathrm{~m}$ has a thickness of $70 \mathrm{~m}$ in the south increasing to $240 \mathrm{~m}$ at the northern edge of the field.

When still only a fraction of the reservoir was appraised, there was hardly any reason to expect substantial subsidence. At the time the known cases of subsidence were all related to shallow, mostly unconsolidated reservoirs. Once the full size of the Groningen gasfield was recognized, it was realized, that noticeable subsidence might occur, given the expected reservoir pressure drop in excess of 300 bar.

Consequently, studies and laboratory measurements on the compaction behavior of the Groningen reservoir were carried out. These were publicly reported in 1973 (NAM, 1973). Geertsma and Van Opstal developed a mathematical model as part of these studies (1973), to enable subsidence predictions in an early stage of field development. The results of the 1971 calculations were presented as contour maps (Geertsema \& Van Opstal, 1973, Figs. 5.9-.5.13). For the year 2050 a maximum of $1 \mathrm{~m}$ subsidence was expected for the central part of the field (Fig. 1).

Development of the Groningen field continued during the following decades and a better understanding of the reservoir behavior was obtained. In addition, the first results from measurement systems came available and new ideas gradually developed on the complex problem of subsidence in general.

It was decided, in liaison with the 'Technical Workgroup' (Government Commission) responsible for monitoring subsidence in Groningen at the time, to compile interim subsidence reports at regular intervals. These reports would give the latest measurement results and interpretations and provide the best possible forecasts on which to base decisions and actions to be taken. The results of the 1975 calculations, using the latest field information at the time such as the extent of the field/pressure distribution and the calculated physical distribution of subsidence, proved to correspond well with data obtained from actual leveling surveys. According to these predictions the maximum subsidence in the year 2050 would amount to about $30 \mathrm{~cm}$.

Based on theoretical scientific work and developments in laboratory measuring techniques a new (empirical) model was applied in 1985 - the Rate Type Compaction Model (De Waal, 1986). Based on the (extrapolated) Plan van Gasafzet 1985 the subsidence in the center of the subsidence bowl in 2025 was predicted to be of the order of $60-70 \mathrm{~cm}$.

In the Subsidence Agreement concluded in 1983 between the Province of Groningen and NAM it was agreed that NAM should publish a prognosis every five years, outlining the predicted future surface subsidence in the province of Groningen resulting from production of natural gas.

In the years preceding the 1990 prognosis, surface measurements and deep compaction data from insitu measurements did show a linear compaction trend with reservoir pressure decline. However, the in situ compaction measurements also indicated a dis- 


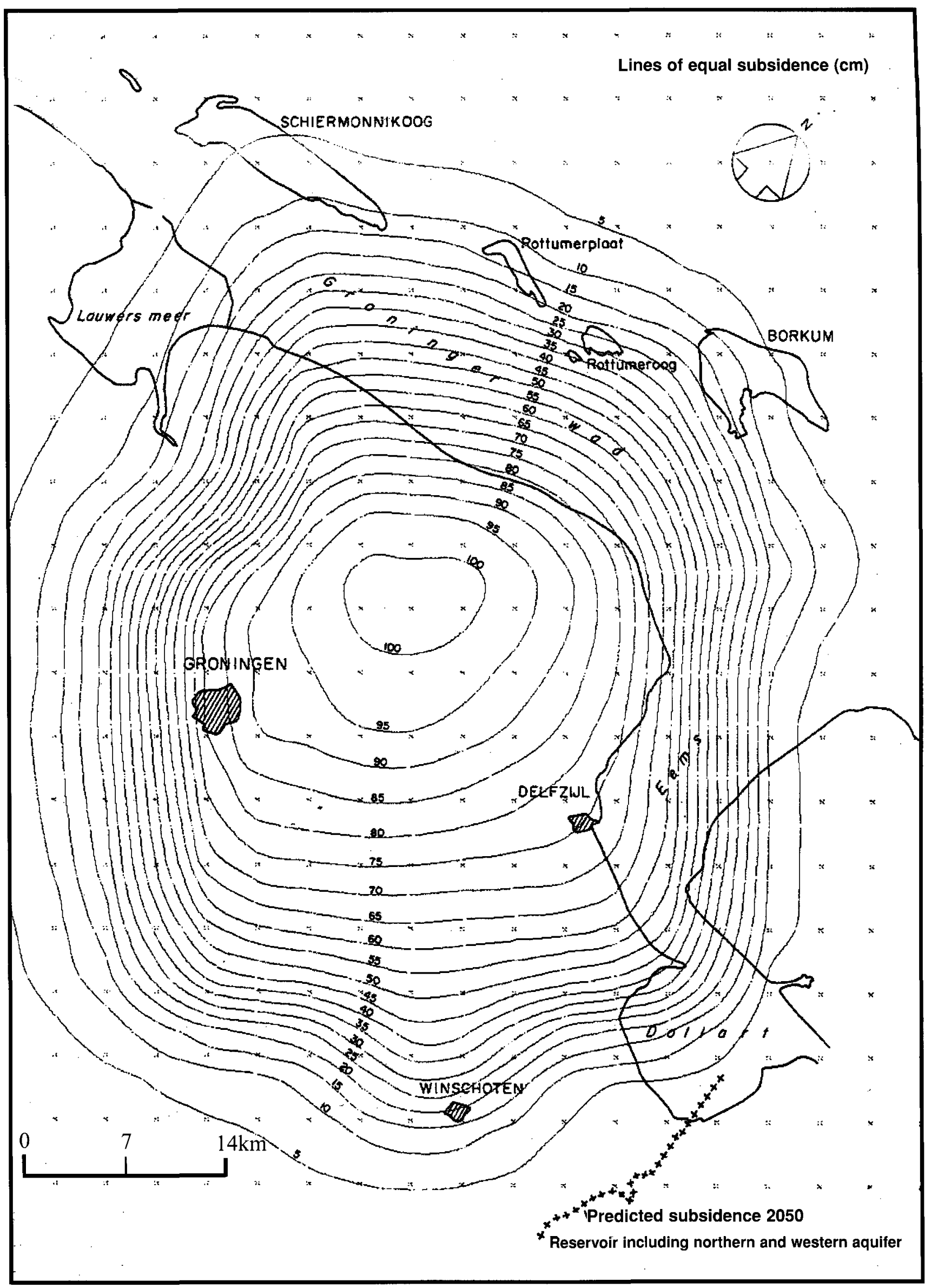

Fig. 1.1971 Groningen Subsidence prognosis in 2050 (KSEPL). 
crepancy between the compaction coefficient measured on core material and the value derived from field observations.

After thorough review of all available data, including the latest information with respect to the reservoir geometry, the pressure depletion distribution for the gas bearing part and aquifer and rock properties formed the basis for the 1990 Groningen Subsidence Prognosis. The expected subsidence at the deepest point in 2050 was now predicted to be of the order of $36-40 \mathrm{~cm}$ (Fig. 2). Since this figure for the predicted maximum subsidence at the time of the Groningen field abandonment was substantially less than the figure reported in the 1985 prognosis, a 'Second Opinion' study was carried out by the Massachusetts Institute of Technology (MIT) at the request of State Supervision of the Mines and the Province of Groningen.

The main conclusions from the MIT investigation were:

- The Rate Type Compaction Model used in previous predictions of subsidence is not appropriate for Groningen.

- The compaction of the reservoir increases approximately linearly with the decrease in gas pressure; the compaction coefficient is approximately constant.

- Creep of either the reservoir rock or surrounding formations will not affect subsidence significantly.

- The monitoring of the surface subsidence by extensive leveling network as well as the in-depth analysis of the data is impressive.

The 1995 Groningen Subsidence Prognosis essentially confirmed the 1990 prognosis. The leveling measurements proved the method used for the 1990 forecast to be correct. The compaction measurements in the deep wells and the results of the leveling measurements over the last five years confirmed the assumption that the reservoir compaction continues to follow the pressure decrease in the reservoir in an essentially linear fashion. The water bearing sandstone layers (aquifers) adjoining the Groningen gasfield are undergoing a decline in pressure because of (limited) pressure communication with the gasfield. Therefore, subsidence will also occur in the areas above these aquifers. This subsidence will take place very slowly. Compared with the 1990 prognosis the shape of the subsidence bowl covers a larger area because new gasfields have been included in the 1995 subsidence prognosis. The increase in the expected maximum subsidence from 36 to 38 centimeters is reflecting the better understanding of the behavior of the bottom water pressure and a lower abandonment pressure (Figure 3).

Since 1995 continuous fundamental-research was directed to investigate the difference between compaction measured in the laboratory and the compaction derived from field data.

The results of this research and the latest field data will be used in the Groningen 2000 subsidence prognosis (in preparation).

\section{Modeling and experiments for compaction pre- diction}

The prediction of subsidence due to reservoir depletion requires sophisticated models, which describe the reservoir compaction behavior and its impact on surface subsidence. Building on the pioneering work of Geertsma (1973), the analytical model SUBCAL has been developed and successfully applied to the Groningen gas field. Computational advances and recent insights in the mechanics of reservoir compaction have triggered the development of GEOMEC: A new NAM-sponsored numerical (finite-element) tool to predict reservoir compaction, subsidence and total stress change. GEOMEC has a number of important features to enable an efficient and yet detailed study of reservoir compaction, and to address its adverse consequences such as subsidence. It is currently being applied to Groningen, and first results indicate that the GEOMEC subsidence predictions agree with previous SUBCAL predictions, and that the assumption of uni-axial compaction in Groningen is correct (only vertical compaction, and little or no horizontal deformation). NAM has also developed a program to determine reservoir compaction by inverting subsidence data, providing important insight in variations in compaction or depletion in the reservoir. The good agreement of the results obtained with different modeling routines, developed by world-class experts, is the valuable result of NAM's careful, systematic and scientifically sound approach to reservoir compaction, giving confidence in the accuracy of the compaction and subsidence prediction in the Groningen gas field.

An important input parameter in compaction modeling is the reservoir compressibility. The value of this parameter can be obtained from in-situ measurements, using the gas-pressure-dependant displacement of radioactive markers placed in wells, or from laboratory experiments on cores taken from the reser- 


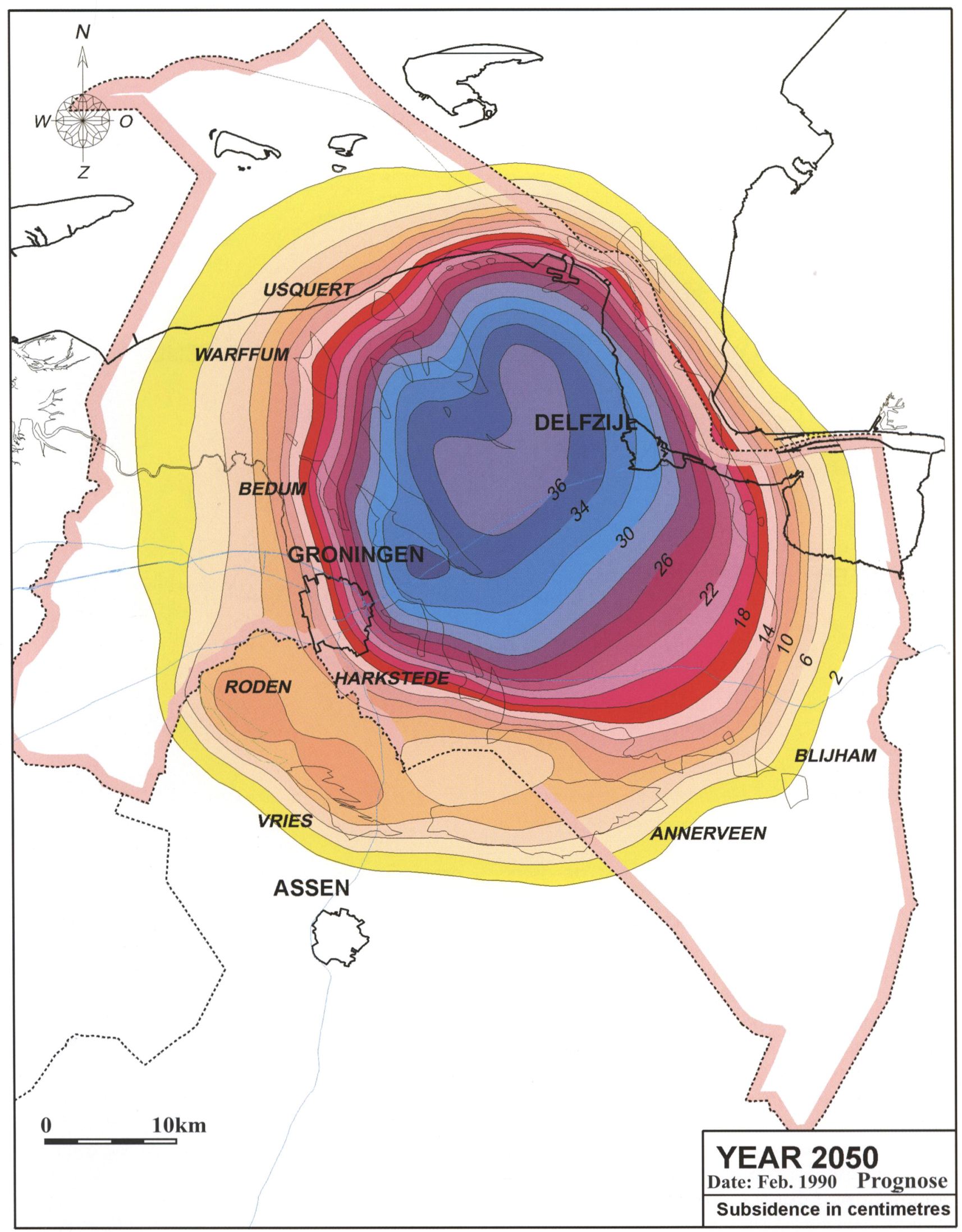

Fig. 2. 1990 Prognosis subsidence in 2050 (NAM).

voir. Regarding the laboratory experiments, NAM has been active in this technology for the last three decades, and tackled a number of technological chal- lenges. Firstly, the sample selection had to be reservoir-representative, both in terms of composition and microstructure (porosity), and there should be no 


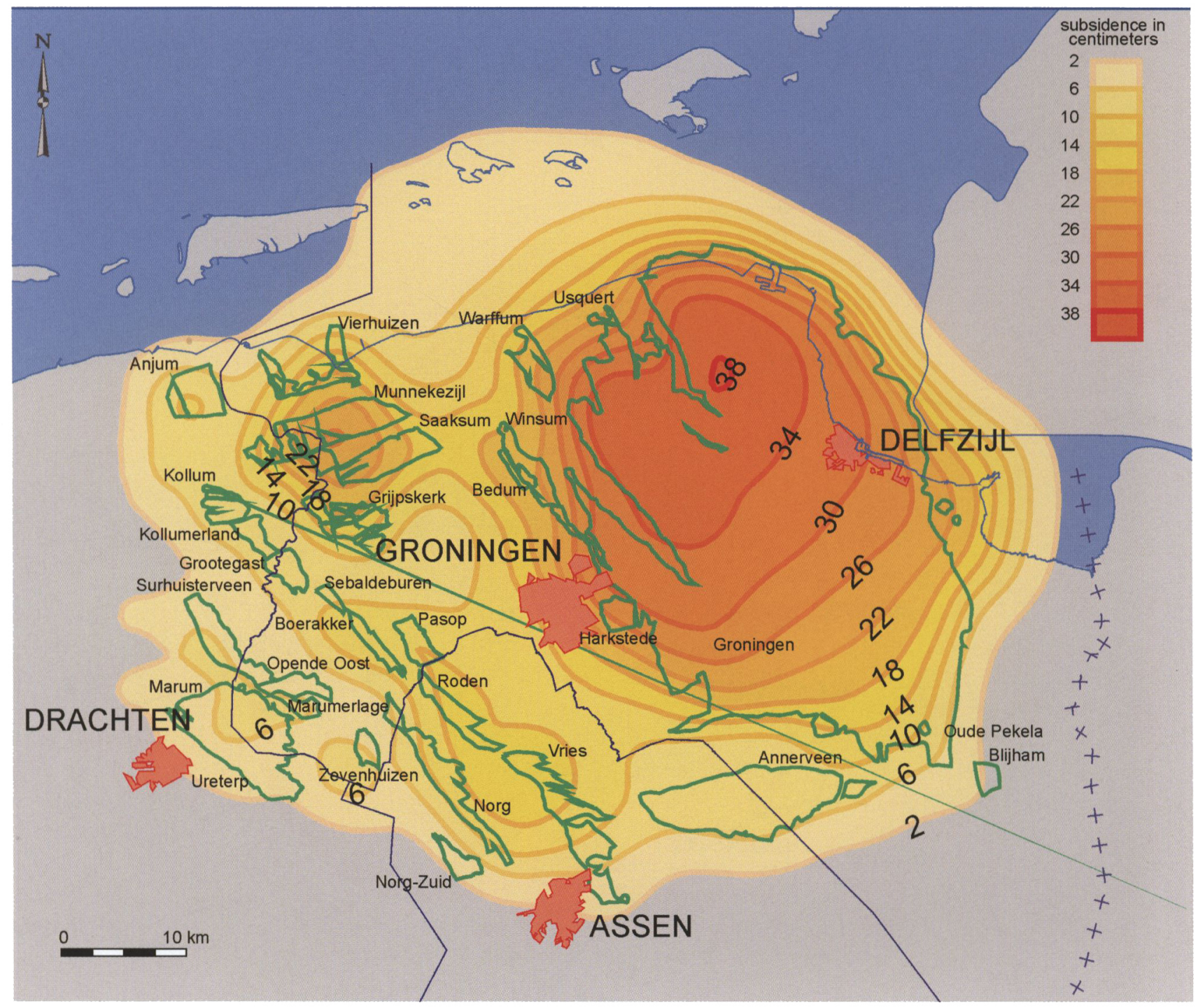

Fig. 3. 1995 Subsidence prognosis Groningen year 2050 (NAM).

core damage. Secondly, compaction test rigs were constructed in which the total vertical stress, the total horizontal stress and the pore fluid (gas) pressure can be applied to the rock samples, in the same way as occurs during the actual Groningen reservoir depletion, and at the reservoir temperature of about $100^{\circ} \mathrm{C}$. The key technology here is the precise measurement of the stress-induced deformation of cylindrical samples of the reservoir rock. Deformation due to compaction in such experiments is on the order of microns, calling for special displacement sensors and extensive calibration. Ultra-sensitive microphones were placed in the loading pistons to monitor the nucleation and growth of micro cracks in-between or inside grains (acoustic emissions), yielding insight in the grainscale compaction mechanisms. Thirdly, the experiments needed to be performed along stress paths, which are representative for the Groningen field, because sandstones show a strong dependence of compressibility on stress path. The first generation of ex- periments were performed under isostatic stress conditions (equal stress increase on all sides), requiring poro-elastic theory to convert the experimental data to different stress/strain conditions. This is no longer needed, as the present apparatuses allow exact reproduction of the field stress path. Given the absence of abundant field stress data for Groningen, the GEOMEC numerical modeling tool was used to calculate these - confirming a stress path associated with uni-axial compaction.

What are the parameters that govern the compressibility in the Groningen reservoir? The main (laboratory) experimental observations can be summarized as follows. Most sandstone samples from the Groningen reservoir have a uni-axial compressibility, which is virtually constant over the range of depletion in the Groningen reservoir; only some high-porosity samples $(>23 \%)$ show an increasing compressibility with increasing stress after about 300 bar depletion (Fig. 
4). The uni-axial compressibility of Groningen sandstone depends linearly on porosity. The large spread in compressibility at a given porosity suggests additional control of rock microstructure on compressibility. The experiments further indicate a strong dependence of compaction on stress path and a small timedependent compaction (creep) resulting from microcrack growth. A model to extrapolate the experimental creep compaction to Groningen depletion time scales (50 years) is currently under development at the Shell Research and Technical Services Laboratory in Rijswijk.

\section{0 years of subsidence monitoring}

To quantify subsidence over the Groningen gasfield, regular leveling surveys have been conducted. In total 27000 elevations of some 2300 benchmarks were obtained in 22 measurement campaigns conducted over the past 40 years. The total costs of these surveys amounted to some 8 million Dutch guilders. These surveys were predominantly conventional spirit leveling surveys with a height accuracy ranging from some $4.5 \mathrm{~mm}$ at a distance of $10 \mathrm{~km}$ to $10.0 \mathrm{~mm}$ at $50 \mathrm{~km}$ from a stable reference point. To cover the Waddenzee and Eems extensions of the subsidence area hydrostatic leveling was employed on 3 separate occasions. The technique depends on the simultaneous reading of the water level at the 2 ends of a hose laid out over a distance of up to $15 \mathrm{~km}$. The method is more accurate than spirit leveling, but 20 times as expensive. From the beginning of the nineties, the Global Positioning System (GPS) was extensively tested. Generally, the results are half as accurate as spirit leveling and significant doubts persist on possible measurement bias. This is due to imperfect atmospheric modeling and left undetected by as yet inadequate data correlation modeling. Lately, the merits of interferometric synthetic aperture radar (InSAR) for Groningen subsidence quantification were assessed. While results in undisturbed arid and urban regions elsewhere in the world with subsidence rates in excess of $3 \mathrm{~mm}$ per month are extremely encouraging, indications for the use of this technique in the generally agricultural Groningen area with a current average subsidence rate of $0.2 \mathrm{~mm}$ per month are unsatisfactory.

Analysis and modeling of the height data has steadily progressed from a simple point-by-point differencing over time with basic outlier detection via an area-byarea place/time polynome fitting to a bowl-wide place/time model fitting. The early point-by-point analysis was often accompanied by a topographic profile over the subsidence area. Ignoring lateral excursions from a straight line through the subsidence area and subsidence due to processes other than gas production frequently resulted in an irregular appearance of such profiles. A plot of observed subsidence as a function of the normalized distance to the center of the subsidence bowl (Fig. 5) overcomes the problem of lateral excursions.

A second problem proved a greater challenge. Before the start of production, $48 \%$ of the topographical benchmarks were classified as unstable, exhibiting subsidence rates in excess of $0.5 \mathrm{~mm} / \mathrm{yr}$. Initially the problem was addressed by rejecting the most unstable

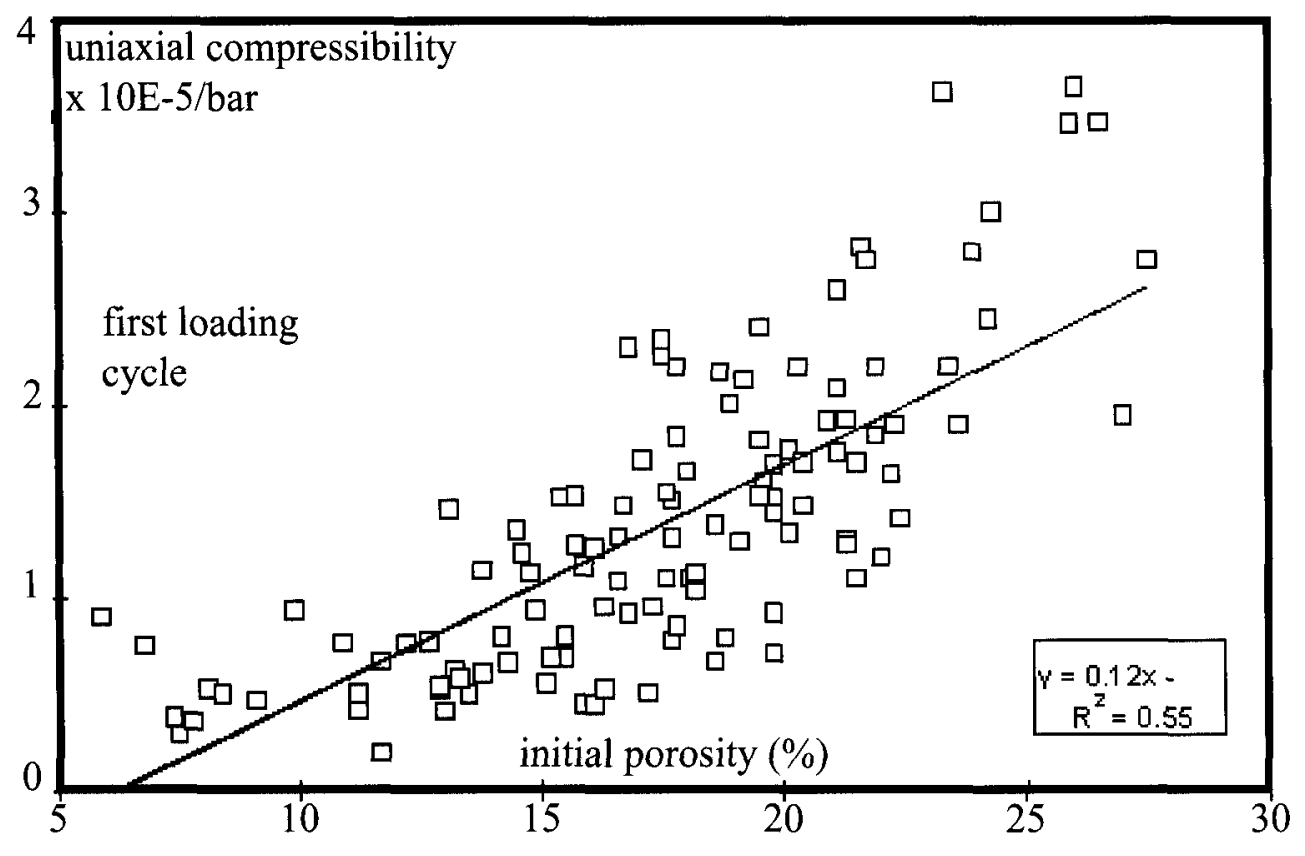

Fig. 4. Groningen gas field. Compilation of all laboratory measured uniaxial compaction data (sandstones) (RTS). 


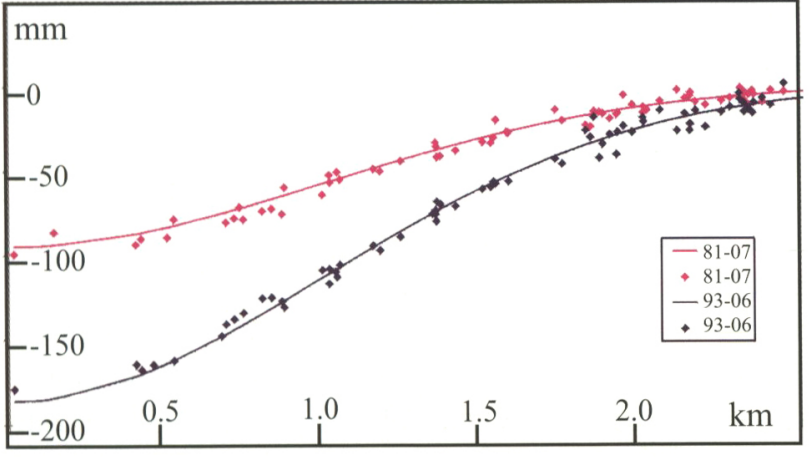

Fig. 5. Subsidence by gasproduction: Model and Observation. Xaxis represents normalized distance in $\mathrm{km}$. Y-axis represents subsidence in mm (NAM).

benchmarks - mostly in buildings with inadequate foundations - and installing new ones nearby in solidly founded man-made structures. This solved the problem for the most extreme cases. However, this still left the bulk of the pre-production unstable benchmarks with subsidence rates between 0.5 and 3 $\mathrm{mm} / \mathrm{yr}$ in the dataset with the resultant corruption of the gas subsidence modeling studies. When the total subsidence rate of these benchmarks after the start of gas production is corrected for subsidence due to hydrocarbon-extraction using a simple bowl-wide time/ place model, the results correlate remarkably well with the subsidence rate before the start of production (Fig. 6). This forms the basis of the correction for subsidence effects that are not related to gas production.

Recent experience has shown, that a simple model characterized by a Gaussian profile, an elliptical horizontal shape and a constant subsidence rate starting some time after start production is capable of describing the subsidence measured thus far to an accuracy of approx. $1 \mathrm{~cm}$ anywhere in the bowl and at anytime in the past. Each distinct reservoir unit requires a separate bowl model of the same type, but with its own parameter values derived during production from leveling surveys over the area of interest. This approach has greatly enhanced our ability to distinguish subsidence effects as to cause as well as permitting optimalization and of survey frequency and benchmark density and distribution.

\section{The consequences of subsidence}

Low-lying countries close to the sea exist in a fragile state of equilibrium with the surface water. Any change in the elevation of the land relative to the water table means, that remedial action soon becomes necessary. What happens if the land drops compared with the water level? Dykes become too low, so safe-

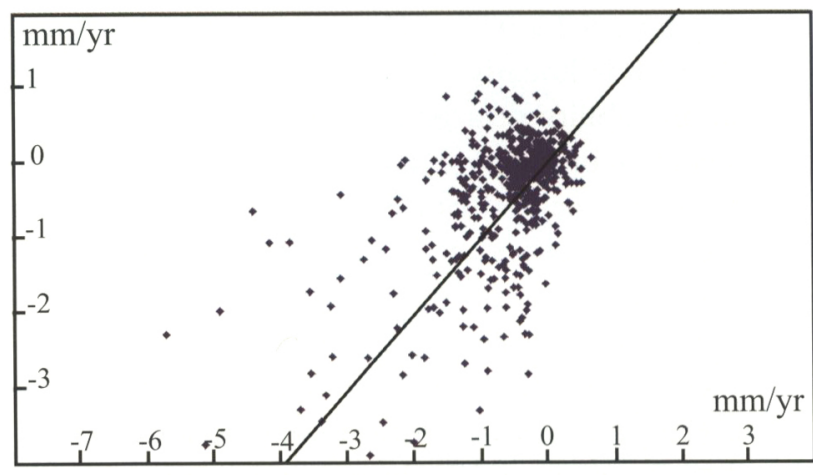

Fig. 6. Correlation before /after gasproduction. $\mathrm{X}$-axis in $\mathrm{mm} / \mathrm{yr}$ before, $\mathrm{Y}$-axis in $\mathrm{mm} / \mathrm{yr}$ after start production (NAM).

guards against flooding become less effective. Headroom under bridges decreases. Less land can be reclaimed from the sea for agricultural purposes and so crop yields drop. Cellars and crawl spaces under buildings can flood, and problems with damp can affect other parts of buildings. In the Netherlands there is a great deal of experience with such problems because the land has been subsiding and sea level has been rising for centuries. Over the last thousand years the relative subsidence in some places has been as much as four to five meters. The remedial measures generally employed to deal with this problem include raising the dykes, reducing water levels and pumping (Fig. 7).

In the nineteen-sixties and seventies, the sea dykes in Groningen were raised by some three to four meters. This was not related to any subsidence caused by natural gas production, but as part of the 'Delta Plan' implemented after the disastrous flood of 1953. Over the years these types of measures have created a mosaic of different landscapes in the Low Countries, typically with different water levels prevailing in each landscape element. This prosaic landscape (Fig. 8) is one of the characteristic features of the Dutch rural heritage.

Generally the subsidence caused by natural gas production is being dealt with using the same measures raising the dykes, reducing water levels and pumping. The amount of subsidence due to gas production, a maximum of some $45 \mathrm{~cm}$, does not necessitate a new or special approach as such. However, as a result of minor local flooding and increased pumping, a debate has started in the Netherlands about whether the margin of comfort has all but gone. The plans to address the consequences of subsidence in Groningen are largely complete and a major part of the required remedial measures have been taken or are being implemented. It is not expected that the ongoing public 


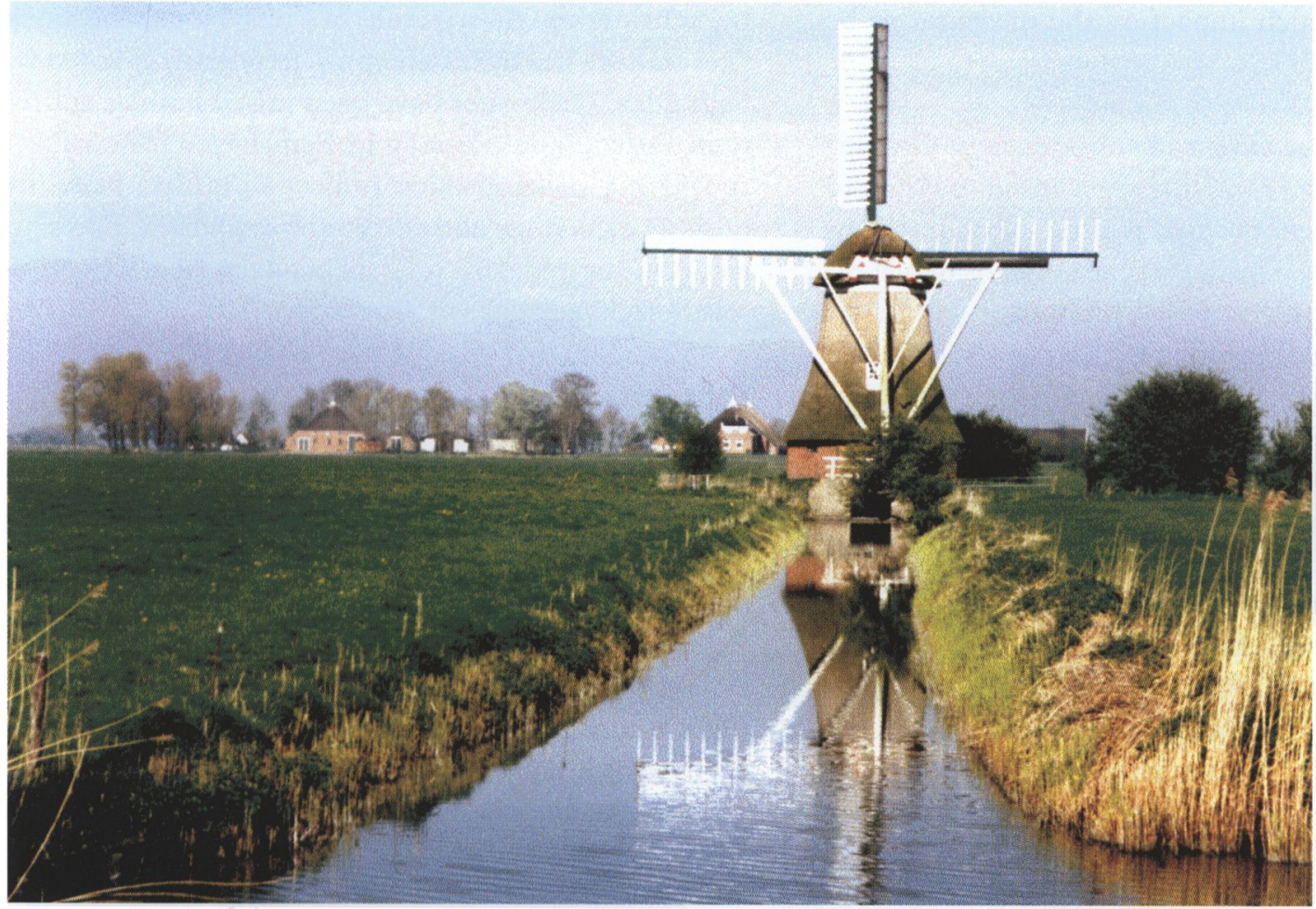

Fig. 7. Photograph of windmill.

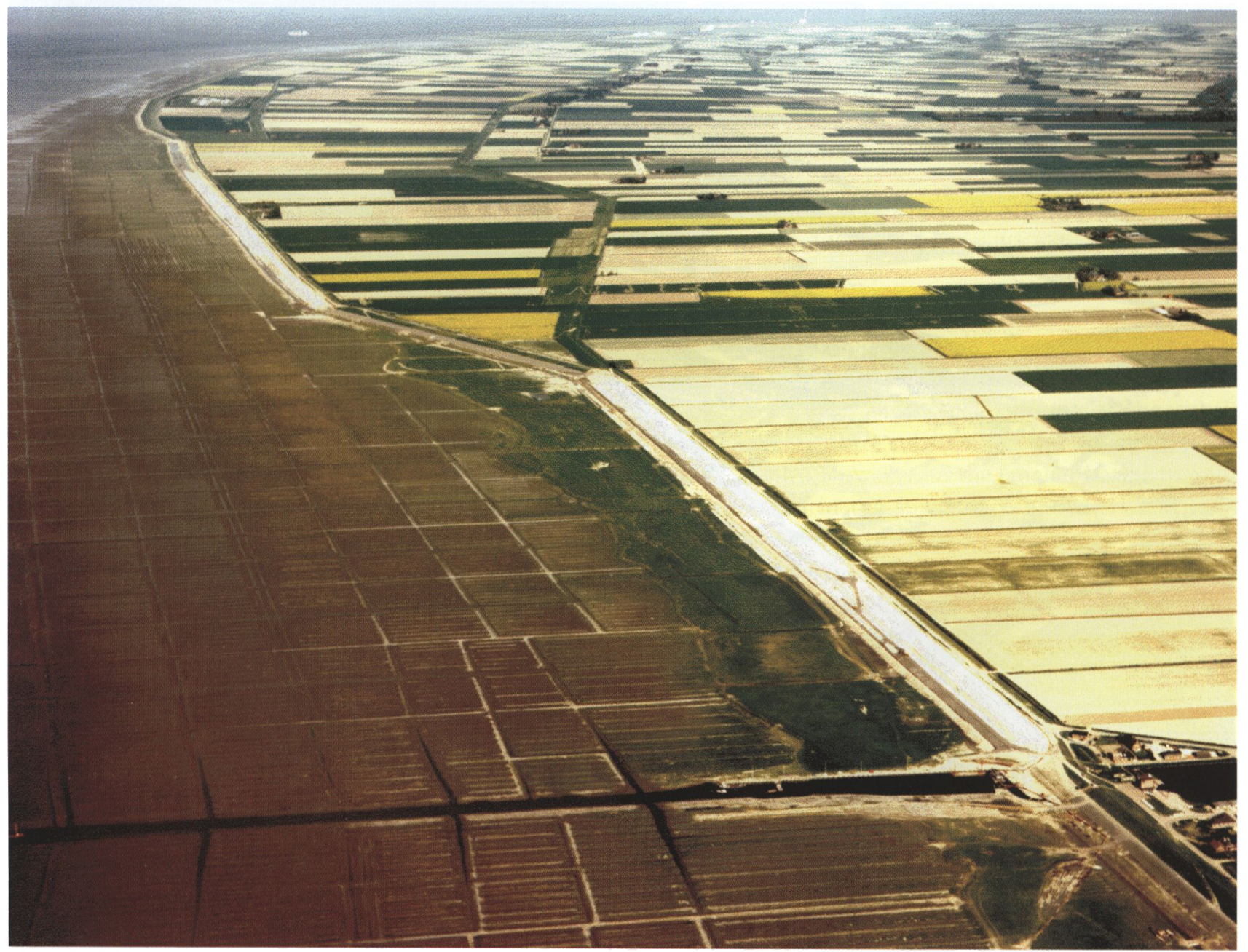

Fig. 8. Aerial photograph of the mosaic landscape (Luchtfoto Aerophoto Eelde). 
debate will have much impact on the measures to be taken.

What precisely is the extent of subsidence in Groningen, what specific problems are caused by it and which measures have been or will be taken to counteract it? (cf. Fig. 3) The occurrence of subsidence reflects the aerial distribution of producing gas fields. The large Groningen gas field is causing a subsidence over a substantial area. The subsiding area has a diameter of about sixty kilometers and the maximum expected subsidence will be some $45 \mathrm{~cm}$ in the deepest part of the subsidence disk. There are also several small subsidence dishes caused by smaller gas fields in the western part of the province. Of these, the Munnekeziil field will have by far the largest subsidence, estimated at $24 \mathrm{~cm}$. If follows from this prediction that virtually the entire sea dyke will be affected by subsidence, to a maximum of approximately 32 $\mathrm{cm}$. As a consequence sooner or later these sea dykes will have to be raised. The seaports of Delfzijl (Fig. 9) and Eemshaven are also located in the region affected by subsidence. As a result of subsidence, the dock sites outside the dykes are more frequently flooded by high tides. These sites have been raised in their entirety in Delfzijl and partially in Eemshaven. The largest subsidence compensation project so far has been the raising of the quay and dock sites in Delfzijl. The project cost around 160 million guilders, of which $90 \%$ was borne by the gas producer NAM.

Subsidence also occurs on the seaward side of the dykes. This is a totally separate subject that is not addressed in detail here. The remedial measures taken so far have been to construct and raise small wicker barrages in order to encourage the silting up of tidal marshes outside the dykes (Fig. 10) so that sedimentation keeps pace with subsidence.

Eight drainage basins partly or completely surrounded by dykes are partly or wholly located within the subsidence area. Each of these basins has its own discharge outlet into the sea. This discharge is being made more difficult as a result of subsidence. The

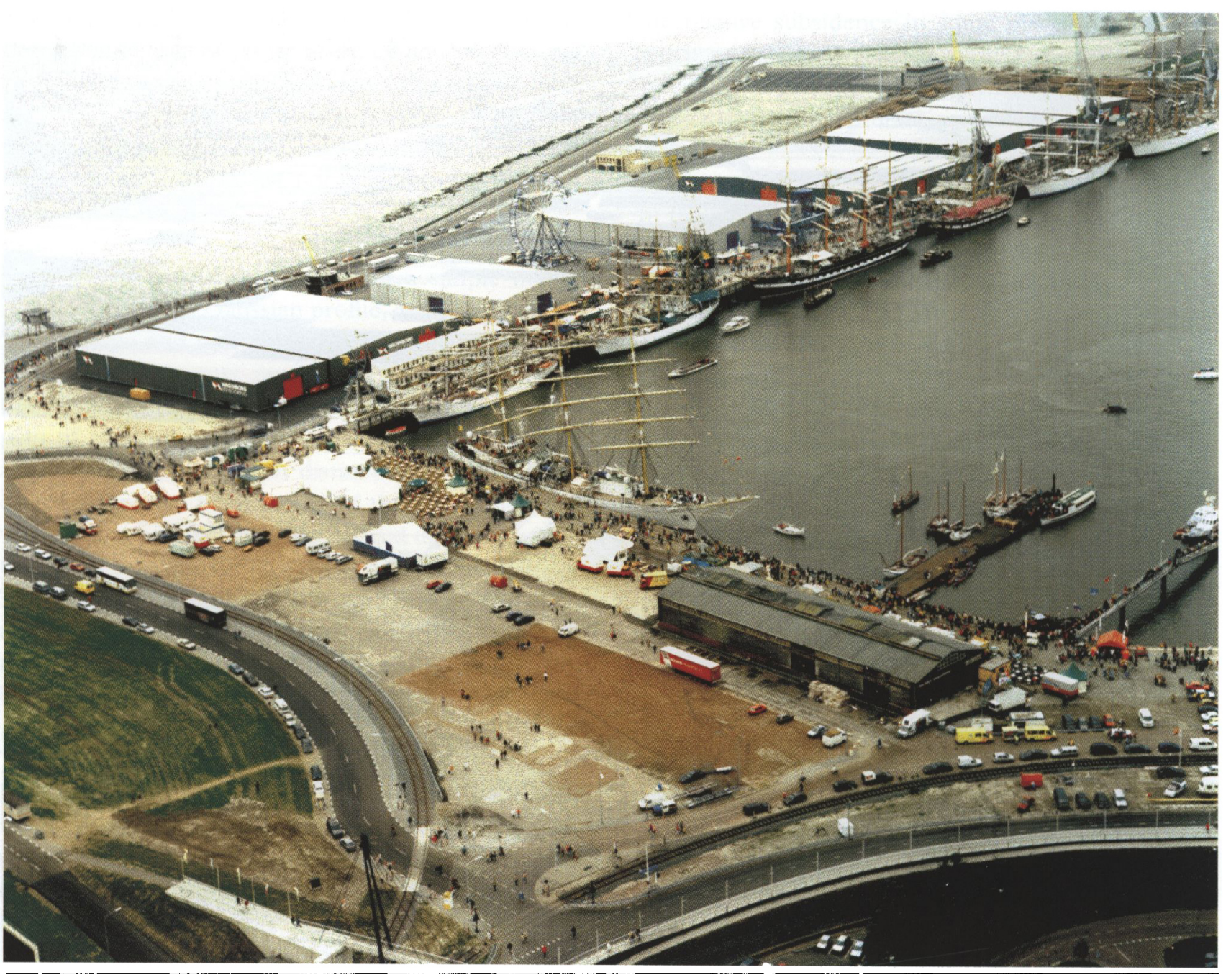

Fig. 9. Photograph of the port of Delfzijl (Luchtfoto Aerophoto Eelde). 


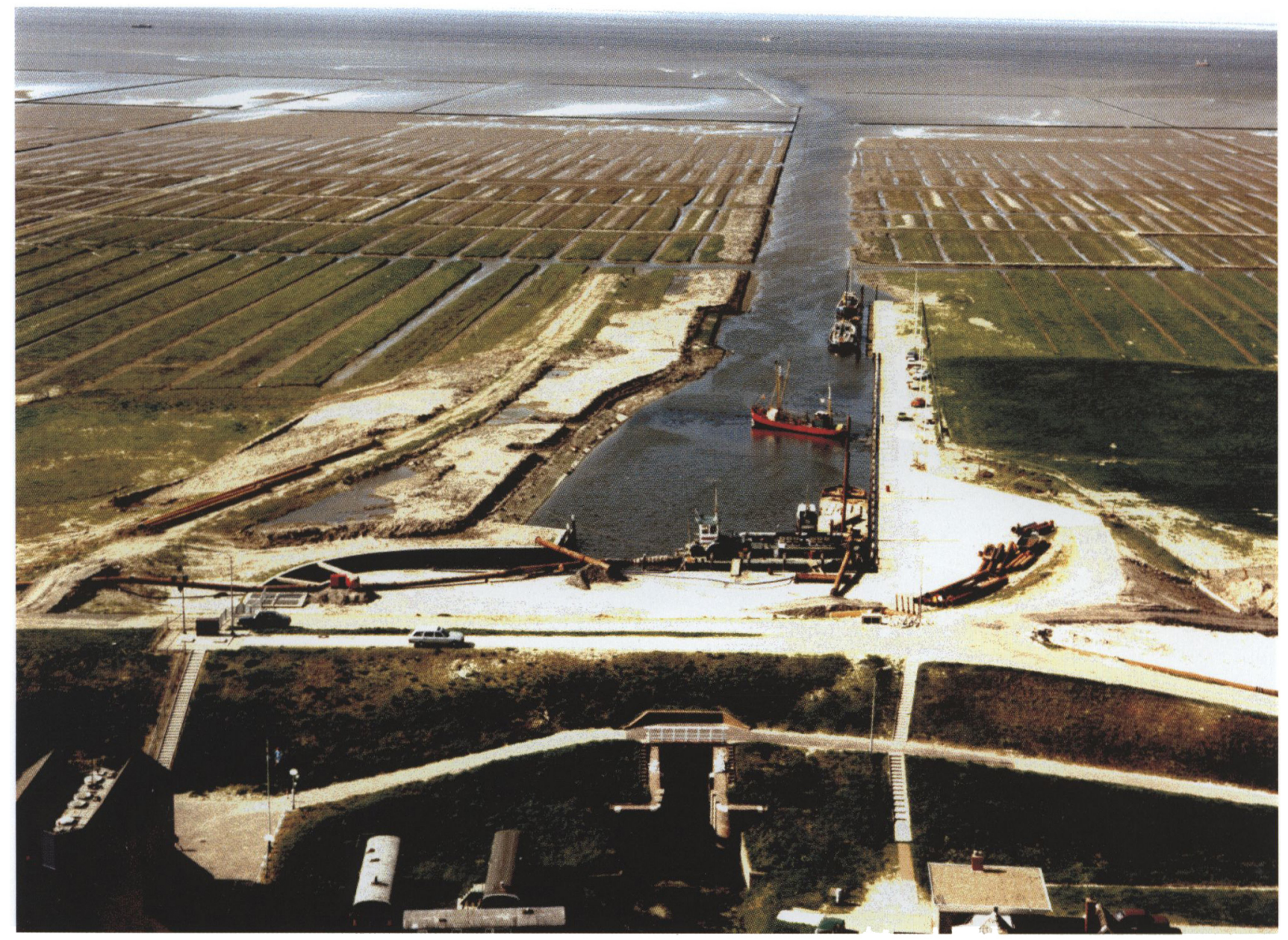

Fig. 10. Photograph of tidal marsh projects in Noordpolderzijl (Luchtfoto Aerophoto Eelde).

maximum surface levels vary from NAP (Amsterdam Ordnance Datum) $+0.62 \mathrm{~m}$ to NAP $-1.40 \mathrm{~m}$. The average high tide in the Eems at Delfziil is NAP +1.31 $\mathrm{m}$ and the average low tide is NAP $-1.68 \mathrm{~m}$. In most of these basins water levels are controlled by a combination of free and pumped drainage. Subsidence reduces the volume of free drainage. Having a greater proportion of pumped drainage or alternatively by creating extra water storage can compensate this. However, this latter approach has not yet been tried because of the significant environmental consequences, for example hundreds of hectares would be involved. Consequently, the existing pumping stations (Fig. 11) have to raise the water to a greater height. Therefore, larger pumping capacity is required and sooner or later the pumping stations will have to be modified. This has already been done in three cases.

The Eemskanaal and Dollard drainage pool, the largest basin, currently drains freely into the sea in two places. Supplementary pumping will be necessary in both places. A pumping station with a capacity of $45 \mathrm{~m}^{3} / \mathrm{second}$ is currently under construction in Termunterzijl. A pumping station will probably also be required in ten years' time in Nieuwe Statenzijl. In theory the problem could also be solved by building extra water storage.

The subsidence does not only affect the basins at the discharge points. Because of the dish shape of the subsiding surface, the actual amount of the subsidence can vary quite substantially within the relatively large basins. However, in the smaller basins there is little variation in the subsidence and the water level can be lowered by the same amount as the subsidence. In the large basins the subsidence can vary by several tens of centimeters. In such cases a simple lowering of the water level cannot be applied throughout. The solution can then be sought in dividing the polder basin into a number of compartments, within which the water levels can be adjusted to the amount of subsidence as closely as possible. Barriers will have to be built between these areas including e.g. a pumping station or a dam with a lock. Another solution involves setting an average water level and then adjusting the dykes, as well as river and canal beds, and bridges. The details of the water management will have to be adjusted in order to manage the drainage 


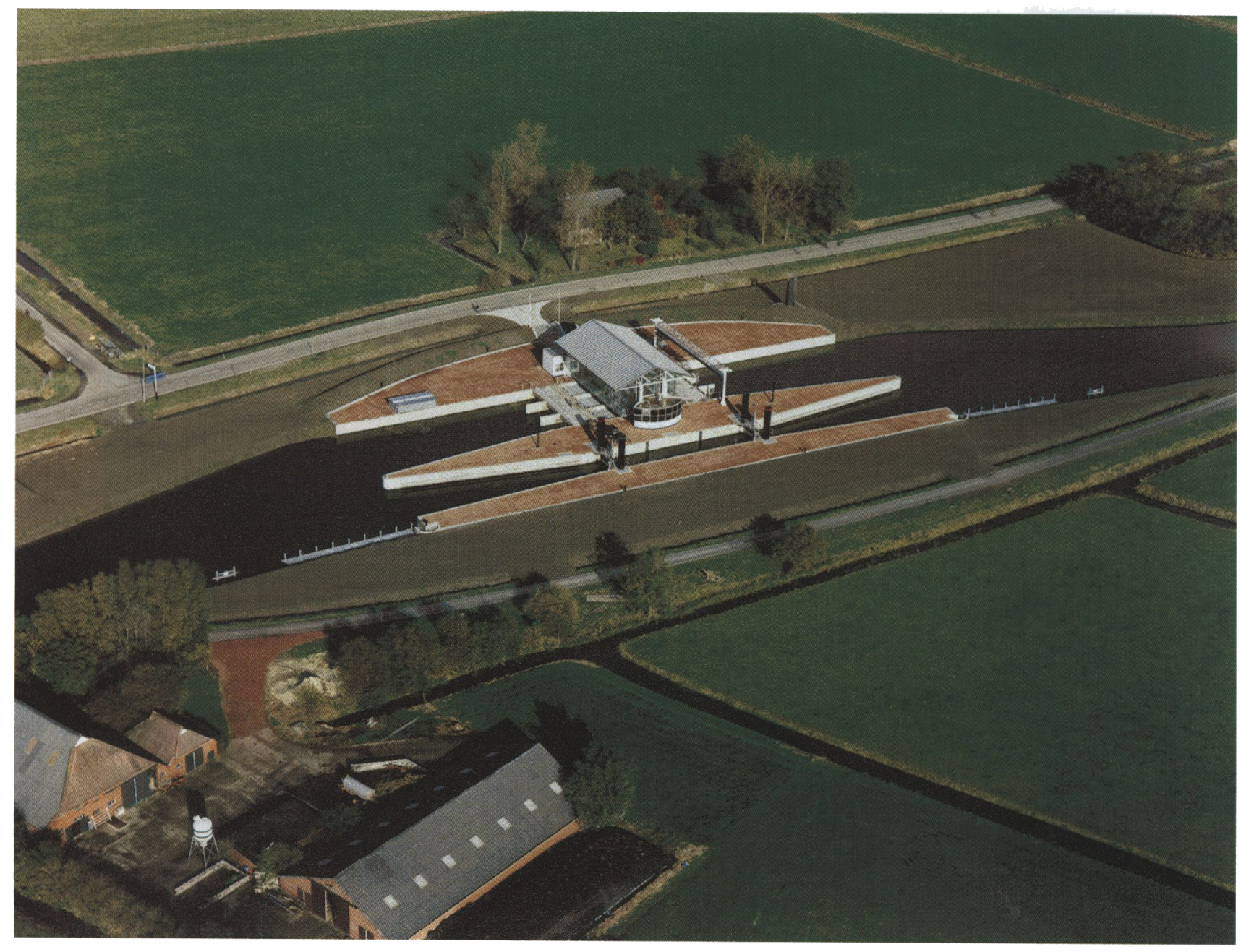

Fig. 11. Pumping station Den Deel (NE of city of Groningen) (Luchtfoto Aerophoto Eelde).

of farms, residential areas and nature reserves in an optimal manner.

In order to address the consequences of subsidence as effectively as possible, the province of Groningen and the Dutch government have jointly entered into an Agreement with NAM in which NAM reimburses the costs of the remedial measures needed to prevent, limit or compensate damage. The agreements stipulate, that there is a Committee that, on the basis of a request, defines the measures, that have to be taken and the costs that NAM is to reimburse. The Committee consists of six members and six deputy members. The province or the government appoint half of the committee members, the other half is appointed by NAM. The decisions of the committee are binding. Government bodies, companies or members of the public can submit requests. Members of the public and organizations wanting to invoke the agreement can become party to the agreement. This is done by signing a declaration to the effect, that the claimant party agrees to be bound by the decisions of the committee and to waive the right to require reimburse- ment from NAM in any other way (through the courts). Under the terms of the agreement NAM will reimburse a maximum amount of NLG 650 million at 1980 prices. The maximum amount under the terms of the agreement with the government is NLG 50 million.

The agreement became effective in 1983. Since then more than 100 members of the public, companies and organizations have become involved in the agreement. NLG 268 million had been paid out by the end of 1998 , of which NLG 45 million was paid to members of the public, companies and associations.

\section{Macro-seismic inquiries}

The occurrence of earthquakes in the provinces of Groningen and Drente has a short history of little over ten years. Seismographs in various networks have detected over 180 earthquakes. These earthquakes are associated with gas extraction from a handful of gas reservoirs in the northerly provinces. A small fraction of the events was actually felt by the public. In such 
cases the press was interested and reported the seismological details of the earthquake the same day. In the early days of the emerging seismicity, the seismic instrumentation available to the Division of Seismology of the Royal Netherlands Meteorological Institute (KNMI) was not adequate, especially to determine the depth of the earthquake. It is particularly important to establish the depth, in order to associate the event confidently with a gas reservoir. This situation prevailed before the current network of borehole seismometers was installed. In general estimation of depth is difficult unless at least one station of a seismometer network is near the epicenter. A macro-seismic survey will provide important additional information in cases where seismometers are lacking.

After the Purmerend earthquake in December 1989 a macro-seismic survey was carried out for the first time. Such a study is an inquiry into the effects of the intensity of the shaking during an earthquake, which depends on the distance to the epicenter. The local population experiences the shaking in different ways and when the shaking is severe enough, damage to buildings may occur. The findings of the enquiry are ranked according to an intensity scale. Within the European Community the European Macro-seismic Scale (EMS) is accepted as an accurate classification of the macro-scale seismic effects as normalized for the different building styles in Europe. Intensity should not be mistaken for the magnitude (on the Richter scale) of an earthquake, which is a measure of the size of the earthquake at the source.

Because earthquakes are rare in the Netherlands, macro-seismic investigations were even rarer and for this case study, the analysis method had to be established first. The macro-seismic inquiry after the Purmerend earthquake proved to be a success. Not only was the epicenter determined accurately, the depth of the earthquake could also be inferred from the data. As a further result a coherent picture of the effects of the earthquake could be constructed, including the emotional reaction of the public to the event. The work done in the field proved to be a signal to the local population of the genuine interest of the authorities in the origin of this earthquake.

In total 150 interviews were held in order to get a representative picture over an area of $30 \mathrm{~km}^{2}$ surrounding Purmerend. The enquiry near Purmerend became a model for subsequent studies in which the data was gathered by different means; e.g. door-to-door interviews, telephone interviews or through advertisements in local newspapers, with all approaches yield- ing essentially the same result. After a fair number of felt earthquakes the relation between intensity at the epicenter and the magnitude of the events could be established, as the depth of all the events was comparable.

One may ask whether this method of investigation is objective enough to be reliable. After a number of such inquiries, the conclusion is a qualified "yes". In a number of cases some caution is justified. The intensity scale is a description of the average effects of the surface shaking during an earthquake; it is a description of several effects in a consistent way. The averaging is done not only over a series of observations, but also over a certain area and over a number of reports from different witnesses of the event. Only if special circumstances occurred during the shaking the results may be influenced. For instance: severe stormy weather, exceptional quiet conditions during the early evening hours or a too small sample of the population being interviewed. The averaging is necessary to level out the unavoidable noise in the observations. The standard deviations of the errors are usually of the order of one half-intensity unit.

With respect to the reporting of damage special care should be exercised. The EMS starts to recognize damage at intensity $\mathrm{V}$ and above. At intensity $\mathrm{V}$ the damage is characterized as "negligible to slight damage" and will occur in $15 \%$ of the most vulnerable buildings according to the EMS. The intensity IV level is strictly speaking without any damage. In a statistical sense in the area of intensity IV, damage should be very rare. It should also be recognized, that large and distant earthquakes have a signature different from small and nearby earthquakes. The EMS does not distinguish between these two different types of events. This complicates the interpretation of the description of the intensity scale specifically with respect to damage patterns. So, it is safe to assume, that damage can occur from intensity IV and higher for this situation of shallow seismicity.

The series of earthquakes in the south of the province of Drente (Fig. 12) near Roswinkel (Fig. 13) provided an excellent opportunity to calibrate the macro-seismic method since in that area a small network of three accelerometers has been installed in order to measure the acceleration during the shaking, even during the largest events. The results showed a good correlation between the accelerations and the measured intensities. 


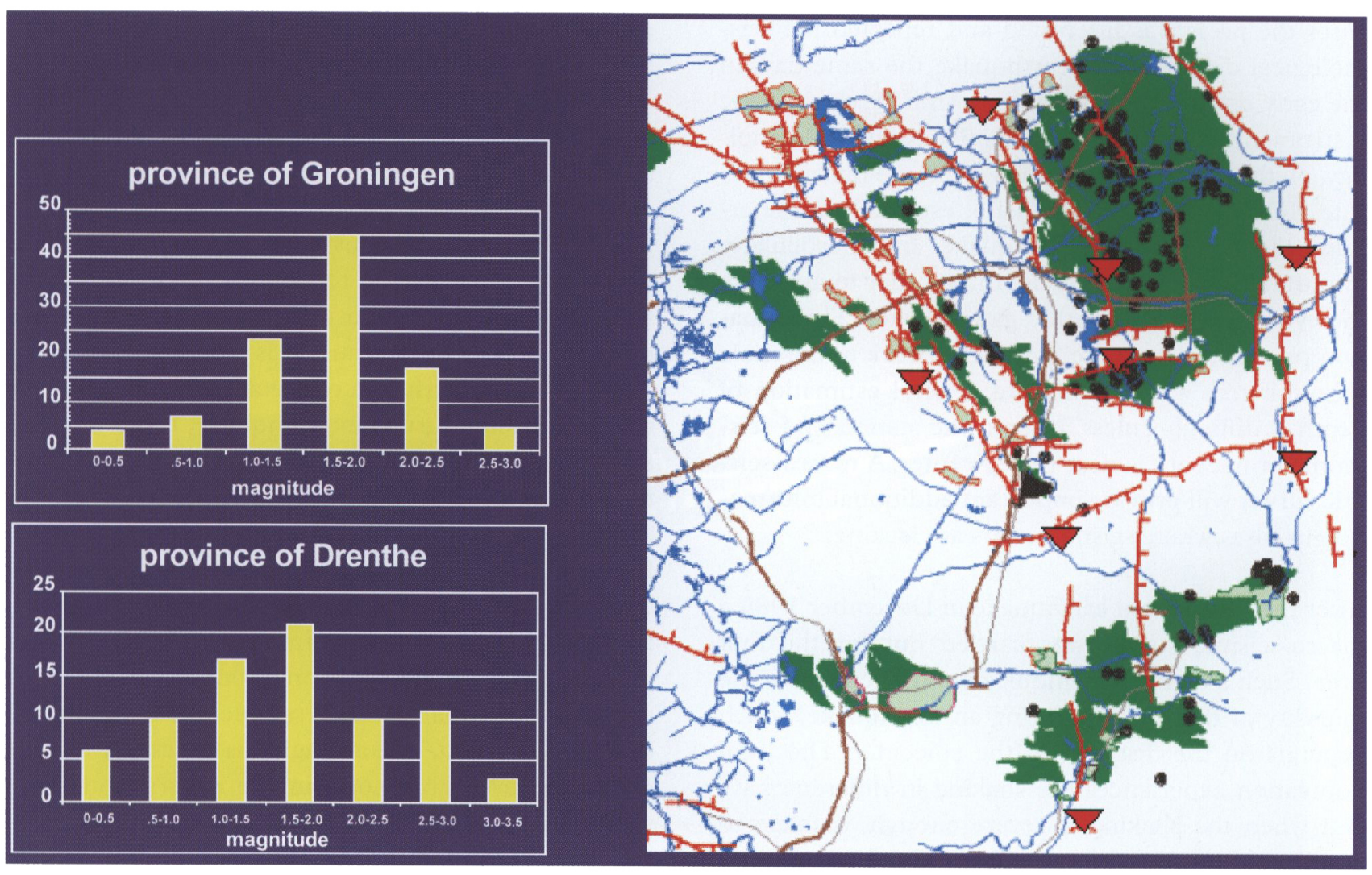

Fig. 12. North Netherlands tremors (December 1986 - January 1999) (NAM).

\section{Society, Subsidence and tremors - in conclusion}

Gas production in most cases will lead to surface subsidence. In practice it is virtually impossible to prevent subsidence caused by gas production with technical measures. For the Groningen field (and some larger gasfields) a substantial area will be affected and maximum subsidence is in the order of some $30-40$ $\mathrm{cm}$. For the smaller fields subsidence is generally less than $10 \mathrm{~cm}$. The surface subsidence manifests itself in the form of a flat, very regular dish. The resulting tilt at groundlevel is so minor, that damage to buildings caused by this process can be ruled out. On the other hand subsidence can have an effect on soil hydrology.

The Agreement 'Overeenkomst Groningen - NAM inzake regeling vergoeding kosten bodemdaling Aardgaswinning 1983' was concluded to establish an arrangement for the reimbursement of costs, that can be attributed to subsidence resulting from the production of natural gas. The 'Commissie Bodemdaling Groningen' (Committee on Surface Subsidence Groningen) was appointed following this agreement.

To monitor reservoir compaction and surface subsidence an extensive monitoring program has been introduced. The program includes yearly leveling surveys and Global Positioning measurements, and pub- lishing the data. Every five years prognoses for the abandonment phase and intermediate years are published. These are based on a three-dimensional grid block model to describe the gas-bearing reservoir and associated water-bearing reservoir.

In addition to prognoses and field measurements, studies are carried out to further fine-tune compaction- and subsidence modeling. Environmental studies and monitoring are performed for environmentally sensitive areas (e.g. Ameland, Waddenzee). If required mitigating measures are initiated to avert negative consequences of subsidence. As a matter of policy, NAM is of the opinion that the consequences of subsidence, resulting from NAM's activities, should stay within agreed societal and ecological boundaries. NAM strives for maximum openness with respect to subsidence and related matters, and on request NAM also provides external parties with further information.

Earthquakes (tremors) are observed since 1986 in the vicinity of producing gasfields in the Northern part of the Netherlands. NAM actively participates in seismicity studies, provides geological and geomechanical data, and initiates studies to enhance scientific understanding of these events. Following the recommendation of the multidisciplinary study, NAM participated 


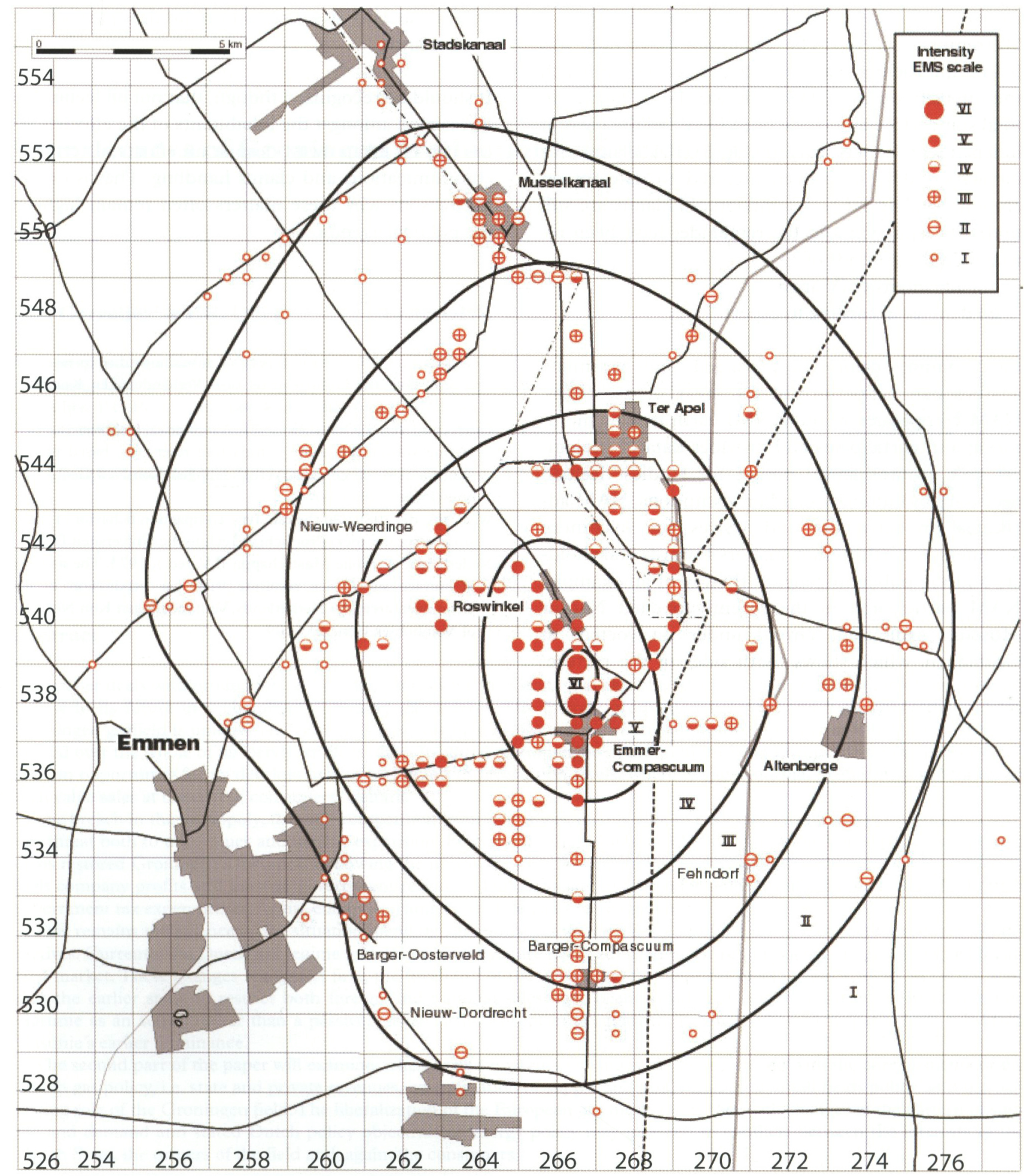

Fig. 13. Intensity map of the Roswinkel earthquake on 19 February 1997 with magnitude 3.4; the largest intensity near the epicentre was VI on the EMS scale (KNMI).

in setting up the North Netherlands Seismic Observation Network, which is operated by the Division of Seismology of the Royal Netherlands Meteorological Institute (KNMI). In addition to this Network accelerometers have been installed in areas, where tremors frequently occurred. In 1995 agreements were concluded with the provinces of Groningen and
Drente as to the way seismic damage claims will be dealt with.

The Ministry of Economic Affairs, Provinces Groningen and Drente, KNMI and NAM, jointly issued the agreement. 
Above the Roswinkel field in southeast Drente over 20 tremors occurred. The maximum magnitude was 3.4 on the Richter scale. For three tremors, for which the intensity on the EMS scale was IV or higher, in total some 515 claims have been filed. On the basis of independent expert investigations 324 claims for damages $(60 \%)$ have been honored to date for an amount totaling NLG 1.1 million. 20 claims are still under investigation and the remainder have been rejected on the grounds of:

- outside intensity IV area;

- no damage according to expert.

Earth tremors cannot be predicted, only sensitivity analysis can be performed for areas or gas fields. NAM co-operates in the KNMI earth tremor monitoring and participates and provides data of geological and geomechanical nature for studies deemed necessary by authorities and/or institutions. NAM advocates pro-activeness and strives for maximum openness in earth tremor matters towards stakeholders and the public in general. By way of an example, NAM participated in the recently opened Natuur Museum exhibition 'Grond onder de voeten' in Groningen, which shows 'both sides of the picture' with regard to gas production in this part of the Netherlands.

It should be recognized though, that not all feelings of uneasiness amongst the inhabitants of the effected areas can be taken away, despite all efforts in terms of communications and claims handling. That is one of the reasons why these matters often remain high on the political agenda.

\section{References}

Geertsma,J., 1973, A basic theory of subsidence due to reservoir compaction: the homogeneous case; Verhandelingen Kon.Ned. Geol.Mijnbouwk.Gen.: 23/43-62.

Geertsma,J. \& van Opstal,G., 1973, A numerical technique for predicting subsidence above compacting reservoirs, based on the nucleus of strain concept; Verhandelingen Kon.Ned.Geol.Mijnbouwk.Gen.: 28 / 63-78.

Waal, J.A. de, 1986, On the rate type compaction behavior of sandstone reservoir rock; Proefschrift Technische Universiteit Delft.

Nederlandse Aardolie Maatschappij B.V. (ed.), 1973, The analysis of surface subsidence resulting from gas production in the Groningen area, the Netherlands; Verhandelingen Kon.Ned.Geol.Mijnbouwk.Gen.: 28 / 109 